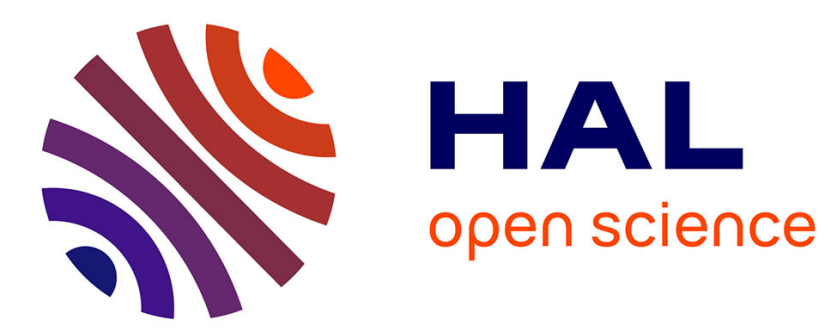

\title{
The Colour of Family Happiness Adoption and the Racial Distribution of Children in Contemporary France
}

\author{
Sébastien Roux
}

\section{To cite this version:}

Sébastien Roux. The Colour of Family Happiness Adoption and the Racial Distribution of Children in Contemporary France. Social Anthropology, 2017, 25 (4), pp.509-524. 10.1111/1469-8676.12451. halshs-01541711v2

\section{HAL Id: halshs-01541711 \\ https://shs.hal.science/halshs-01541711v2}

Submitted on 23 Jun 2017

HAL is a multi-disciplinary open access archive for the deposit and dissemination of scientific research documents, whether they are published or not. The documents may come from teaching and research institutions in France or abroad, or from public or private research centers.
L'archive ouverte pluridisciplinaire HAL, est destinée au dépôt et à la diffusion de documents scientifiques de niveau recherche, publiés ou non, émanant des établissements d'enseignement et de recherche français ou étrangers, des laboratoires publics ou privés. 


\title{
The Colour of Family Happiness
}

\section{Adoption and the Racial Distribution of Children in Contemporary France}

\begin{abstract}
In France, the notion of "race" itself - which echoes both (post-)colonialist discourses and a long history of state-regulated racism - is usually publicly inexpressible, despite its implicit presence that nonetheless saturates public debates. However, in some specific cases, such as transnational adoption, the verbalisation of racial preferences and desires are encouraged by social workers and family experts, as a mean to prevent racism. This article aims to analyse the kind of practical institutional framing which produces and supports such a verbalisation, and to explore its consequences with respect to the definition of racial hierarchies. Hence, instead of considering the preference of skin colour as a pre-established parental desire that informs the racial distribution of children, I suggest focusing on the French case to analyse the racialization of familial desires produced by and for the apparatus that frames adoption. Thus, by concentrating on the governance of family intimacy, this article aims to question the social dynamics that construct race as a meaningful performative category requiring professional expertise and action, that allow its public expression, and that even facilitate the verbalisation of racial preferences in an institutional context supposedly defined by colour-blindness.
\end{abstract}

\section{Keywords}

adoption, race, family, France, institutions 
June 2013. I join Laura, a social worker from the local Adoption Bureau, to visit a couple aiming to adopt a child from Vietnam. We go to Renon, a small town of 10,000 inhabitants located in the West of France ${ }^{i}$. Mrs. Lanielle is 45 years old, her husband 39. They started their adoption process 7 years ago. Although they obtained the required administrative certification (agrément) without difficulties, the Lanielles have experienced a series of problems ever since, and have currently put their lives on hold, waiting for a child who has yet to arrive. Mrs. Lanielle teaches in a private Catholic junior high school. Her husband smiles at us gently, with a debonair appearance which contrasts with his wife's weary sternness. He works as a logistics engineer in a local company. Promptly, Mr. Lanielle invites Laura and me to sit down at the dining room table. A thick binder marked "Adoption" sits open on the white lace doily that covers the table, attesting to the incessant efforts, over several years, of the couple; but also to their tenacity and persistent determination to adopt.

As required by French law, the Lanielles have been previously certified for a child matching specific characteristics only: less than three years old, and without any health issues. The couple's only stated preference with regard to their child, during their previous administrative certification process, concerned age; they never overtly expressed any specific desire in terms of gender or race. When I ask them about the possibility of adopting a child in France instead of turning to international adoption - without mentioning any racial criteria Mrs. Lanielle explains to me:

"We've been to a meeting about that, but I did not feel ready. To me, if we adopt a child, I need it to be visible. The situation had to be clear; otherwise, it could have been a child my husband had with another woman, or a child I had with another man... [Nodding] Here, it would be more clear."

Here, a "more clear" situation involves un-whiteness, and racial differences that have to "be visible". To Mrs. Lanielle, such visibility means that at first glance the particularity - 
or even the strangeness - of her kinship, might justify her age, and demonstrate the value of her humanitarian approach. I question the couple further about their desire for racial difference by asking them what colour of skin they would prefer their child to have. A little embarrassed, they answer that they "are much more attracted to Asia than to Africa". Laura the social worker I am accompanying - accepts without batting an eye this public manifestation of a racialized desire.

Adoptive parents constantly anticipate the kind of child they want, they desire, they expect (Marre 2007). As social sciences have already demonstrated, reproduction issues are always-already framed with racial anxieties (Dorlin 2006; Saada 2012; Stoler 2010), as 'race' delineates borders and boundaries between individuals, groups, and classes. Adoption is no different. As with new reproductive technologies (Deomampo 2016; Wade 2007), adoption is a way of engendering that always results from a (very) long ordeal in which applicants are regularly invited to think, to formulate, and to express phenotypical preferences, but also more broadly - to verbalize their "attraction", their "interest", or their "preference" for a "place", a "culture" or a "country" constructed as fantasised alterities. These loci are supposed to be - at the same time - different and exterior, but close enough to produce a child who is expected to join and to integrate within his/her new family without too many difficulties or "adjustments".

Studies in social anthropology concerning the relationship between race and adoptive parental desires have already examined this political geography of racialized desires. Developed for the most part from a US perspective, these analyses have documented the historical hierarchies that organise the changing desirability of spaces, and of the children who embody these racialized definition of otherness. These studies have notably highlighted the higher desirability for Asian children on the part of white North American adoptive parents from the middle class (Choy 2013; Dorow 2006; Eng 2010), and their partial rejection 
of black children or those from other racial minorities. In the US, "transracial",ii adoption has been constructed as a political issue with a specific genealogy (Jerng 2010; Seligman 2013), deeply informed by the prominent critique of the National Association of Black Social Workers (NABSW). In 1972, the NABSW recommended intra-familial racial homogeneity in order to limit the domestic experience of racism for black children, to strengthen racial solidarity, and to end the appropriation of black children by unfertile white parents (Briggs 2012; Melosh 2002). Perceived as a political and social problem ever since, transracial adoption has been regularly debated (such as, for example, during the Multi-Ethnic and InterEthnic Placement Acts of 1994 and 1996), with such debates tending to form around the issues of children's racial identities and the racial power relations that organize their distribution.

However, few studies focus on other national contexts, where 'race' and its genealogy have different meanings and consequences. In France, the notion of "race" itself - which echoes both (post-)colonialist discourses and a long history of state-regulated racism - is usually publicly inexpressible (Lieberman 2004). Based upon an emancipatory, universalist ideal since the 1789 Revolution, the French Republic thinks of itself as an abstraction which treats its citizens colour-blindly. Officially, the State and its agents (eg, social workers working in the field of adoption) have no right to record skin colour, to mention phenotypical differences, nor to use any files or documents mentioning "race" or "ethnicity" as categories (Sabbagh and Peer 2008). As such, if France has a specific "politics of otherness" (Mazouz 2017), the way it deals with alterity is symptomatic of a national ambiguity towards colourblind republicanism; it is acknowledged that racial domination and social exclusion are intertwined (Fassin and Fassin 2006), but racial diversity remains unspeakable in the public sphere, or - more precisely - can never be a criterion to define public policy. Social servants are required to process without mentioning, to act without pointing, and to deploy a practical 
activity that is, at the same time and paradoxically, white and universal, racialised and colourblind.

As a consequence, what is striking in the French adoption case is less the synchronization of parental racial desires whereby some spaces are fantasized over others, which is internationally observed, than the local possibility to publicly express any such racial will, and to make "race" an active - if tacit - category of action. First, this article aims to analyse the kind of practical institutional framing which produces and supports such verbalisation of ambivalent desires, and to explore its consequences. Hence, instead of considering the preference of skin colour as a pre-established parental desire, I suggest focusing on the French case to analyse the racialization of familial desires produced by and for the apparatus that frames adoption. Then, still focusing on adoption, I analyse more specifically how "race" has been supplanted by the notion of "culture", which is used as a local expedient to deal with racialized attributes. However, this shift is not a mere replacement of categories. If "race" is perceived, locally, as a notion that divides and segregates, "culture" is promoted as an embodied resource that has to be protected and defended, even if it produces differences and hierarchies. Finally, by focusing on adoption and on the government of intimacy, this article aims to understand how racialized policies are implemented by a supposedly colour-blind society, and how the "best" possible domestic arrangements encourage racial hierarchies - promoting a coloured definition of happiness and family love.

The qualitative data used in this article have been collected during an ethnographic fieldwork conducted between April and August 2013, in a French bureau charged with administering adoption (both nationally and internationally). I spent eight hours a day in a local Adoption Bureau observing the daily activities of a dozen female professionals specialised in adoption certification and support. In total, more than 350 hours were spent 
with social workers and psychologists who allowed me to attend face-to-face interviews, home visits, staff meetings, archives, commissions, cooperative initiatives with local associations, etc. This work is part of a broader project that aims to understand the diversity of actors who produce and regulate the transnational adoption apparatus (social workers and psychologists, diplomats, orphanages, activists, paediatricians, philanthropists, etc. ${ }^{\mathrm{iii}}$ Other on-going fieldworks are currently conducted in France, Vietnam, and Ethiopia, focusing more specifically on the norms and values that traverse the world of international adoption, and on the moralization and ethicization processes that transform, frame and organize these particular South to North migrations.

\section{A brief institutional genealogy}

A fairly substantial literature in social anthropology already deals with the circulation of children from South to North for family-building purposes. Although some studies focus on the southern countries where children originate (Leinaweaver 2008), or concentrate on those who have surrendered - or entrusted - their children to adoptive parents (Briggs 2012), most of the current literature analyse the way new families and their social environments welcome and integrate these children (or, sometimes reject them), and how race is perceived and constructed as an issue for families, adoptees, and intermediaries (Treitler 2014). As Signe Howell suggests (2009), these works have mostly shed light on the affective construction of adoptive families and its emotional impact (Volkman 2005; Howell and Marre 2006); on the political and ethical issues related to the denial of power relations that frames these intra-familial commoditized relations (Zelizer 1994); on the identity crisis that some adoptive children may experience and its political meaning (Eng 2010); and on adoptees' always-incomplete racial, social and familial integration (Kim and Yngvesson 2011). 
However, very few studies have focused on the administrative apparatuses that render possible the matching between adoptive parents and adoptees, their political and moral foundations, and their impacts on both applicants' subjectivities and state policies. Focusing on the French case, however, is a way to shed light upon practical forms of the government of intimacy and institutional dynamics that allow (or impede) the making of families (Perreau 2014), that hierarchize desires and possibilities, and that define new ethical standards in the management of private lives. Indeed, adoption has been publicly regulated and administered in France for more than a century, gradually transforming from a contractualization regime between parents and children - or the people in charge of representing them - to an administrative regime where public authorities are in charge of both framing the circulation of children and deploying a peculiar form of governmentality focusing on the assessment and transformation of parental abilities (Roux and Vozari, 2017). However, before examining current practices, a brief genealogy of adoption remains necessary, in order to understand some of the political and moral stakes located "at the heart of the state" (Fassin et al., 2015), and the dynamics of institutional logic that acts upon subjects, transforms them, and produces new affects, desires, and family assemblages.

At the end of the nineteenth century, a long-term reform movement produced a shift in the way children had been previously considered in France. Minors gradually became recognized as constitutively fragile subjects who had to be protected. Expert knowledge, dedicated institutions, and bodies of professionals were formalized to manage a newly defined "problematic" population, especially in the fields of (penal) justice, medicine, and education (Foucault, 2004a). France encouraged a specific policy towards childhood which established a public duty of care and responsibility. The foundations of modern adoption are rooted in this reformative process, and in the sense of responsibility (collective and individual) it has encouraged. 
World War I can be considered as the event that established the grounds upon which the treatment of orphaned children has been built. In July 1917, a specific status was adopted to put a child deprived of his/her parents by the war under the benevolent and protective gaze of the national community. "Pupils of the Nation" were protected by the "French Republic" to remedy the harms caused by the war effort (Denéchère 2011). Adoption was then perceived as a remedy to war casualties, healing the wounds of orphans, unfertile couples and a generally damaged populace. However, until World War II, few couples adopted in France: No more than 1200 children per year were adopted at the end of the 1930s. Plus, adoption remained almost exclusively intra-national: the supply of available children was superior to their demand, and racial and cultural homogeneity was privileged amongst families ${ }^{\mathrm{iv}}$. In this specific context, new laws were passed to bring adoption into alignment with procreation. A statutory order was passed the $29^{\text {th }}$ of July 1939, allowing the termination of any link between an adoptive child and his/her birth parents by order of the judge. During Vichy France (19401944) this measure, and others like it (lowering of the minimal age required to adopt, exclusive transmission of the adoptive parents' family name, erasure of children's pasts prior to their adoption, etc.), were used to encourage the construction of adoptive families, modelling their domestic arrangement on biological filiation.

Legislative reforms followed to accelerate this dynamic, and the regime of "full adoption" (adoption plénière) was created in 1966. Here, birth filiation is wholly replaced by adoption, irrevocably and permanently; adoptees are officially "born" from their adoptive parents, obliterating an initial condition implicitly perceived as problematic. In that context, secrecy towards birth was encouraged to prevent any social or judicial trace from soiling the juxtaposition of adoption and reproduction. Secrecy was then promoted and implemented to legitimate adoption, and to protect the reputations of parents and children by concealing the supposed social artifice that laid at the foundation of this familial assemblage. However, by 
doing so, this apparatus paradoxically reinforced the norm according to which biological filiation was most desirable, and rendered for decades "origins" and "conditions of birth" almost unspeakable in the French context.

Since the 1970s, the development of social institutions dedicated to the protection of the child has led to a decrease of national adoption. Consequently, applicants started looking south to fulfil their parental desires, and the rate of international adoption rose dramatically during the 1970 s and the 1980 s. These new migrations brought more racial diversity to adoptive families, and entailed a more complex apparatus to relate children and parents. The previous regime of conformation and secrecy that prevailed mid-century has been gradually replaced by a humanitarian regime, which deploys compensatory politics to offer suffering children from abroad (whether fantasized or real) a "comforting" home and "generous" parents, rather than silence and shame vis-à-vis their original condition.

Children's “adoptability" started to emerge as an ethical and political issue in the 1970s. How to be sure children were "true" orphans? Or, if they were not, and birth parents were still alive, how to prevent applicants from exploiting their Western privilege to fulfil parental desires? In brief, how to be sure applicants acted "ethically" with regard to the norms and values that prevailed? However, as it remained impossible, for reasons of sovereignty, to determine the adoptability of children from abroad, the French administrative gaze shifted from children to parents. Doubts about children's origins and adoptability were transferred to applicants, whose potential desires and abilities have been ever since carefully scrutinized.

Therefore, new modes of technique, knowledge and expertise have been deployed to interrogate parenting skills. In 1984, an administrative parental certification (agrément) was established as a prerequisite for adopting, at first for national procedures only, and extended to international adoption the year after. This institutional authorization is now mandatory. Adoption Bureaus deliver it at the local district level (département). This certification is valid 
for 5 years, and it can be renewed. Social workers and psychologists are in charge of conducting interviews to investigate applicants' material and psychological lives. Two or three in-depth interviews (from 1 to 3 hours) are held with candidates (individually or/and as a couple), followed by a home visit. Reports are transmitted to the Certification Commission (Commission d'agrément) which is officially presided by a local elected representative. According to the judicial and professional ideology that characterizes the world of adoption, social services never consider it their duty to facilitate the fulfilment of applicants' desires, but rather to assess candidates' abilities to "respond to children needs".

Officially, the rate of refusal for certification applicants is low: less than $10 \%$ are denied, even if the rate of refusal may vary from $0 \%$ to $35 \%$, depending on district and bureau (Colombani 2005). However, institutional activity cannot be reduced to evaluation only; professionals are also in charge of educating parents by "supporting" them during the "process they undergo". To these professionals, the vulnerability of adoptive children justifies particular control and regulation policies, which "put applicants to work" during the time they wait for a child, in order to make them "specify their project". Social workers and psychologists encourage candidates to "project themselves", that is to say "become aware of" (i.e. verbalize) the "specificity of adoptive children". Consequently, interviews conducted during the certification process do not only serve the purpose of evaluating candidates or assessing their relative conformity to a universalized family norm (which defines as its standard white, heterosexual, unfertile couples of procreative age). In addition, professionals seek to convince applicants of the rightfulness of their professional knowledge, and of the necessity to embody it to manage a future child at risk. Thus, workers aim to reduce familial risks by determining if applicants will adequately take on their duties towards "a child that has been abandoned once already". At the same time, this policy toward "parenthood" aids in selecting and supporting individuals: parental abilities are evaluated while candidates are 
encouraged to "work on themselves", by adjusting their desires, feelings, and practices. This process is similar to a form of governmentality that focuses on "prevention", anticipation, verbalization and subjectivization, where parental skills are less quantified than produced, and where as much attention is given to transforming an individual's sense of interiority as is paid to "selecting" him or her. (Rose 1990).

\section{Assessing the risks of racism}

At the beginning of the certification process, when applicants first make contact with the unit, they are asked to complete a form to specify their expectations and wishes. In the unit I joined, candidates were asked two questions, amidst other details and administrative information: "Why do you want to adopt a child?" and "Do you have any desires about the child or the children you want to adopt (age, number, siblings, origin, health, sex...)?" The criterion of "origin" is ambiguous. As applicants are aware, for the most part, of the difficulty in adopting and of the selectivity of the process, so they often provide neutral answers. Admittedly, it is likely that the vast majority of candidates do not consider skin colour as meaningful. However, their silence may also be the consequence of an anticipated accusation of racism (and, therefore, a strategic management of their subsequent relations with social workers and psychologists), as much as the product of a rational will to maximize their chances of adopting by remaining open to diverse possibilities. Except for a few special cases, most candidates did not express specific phenotypic desires: racial preferences remained generally unexpressed, at least initially. Most applicants, however, gradually asserted their will as the accompanying process went along. These discursive evolutions concerning racial desires - from their secrecy to their statement- even rendered the expression of colour preferences of superior value. Indeed, professionals often understand the non-expression of a 
will as a trace of the "parental project immaturity". This performative verbalization of "one's parental project" contains a racial dimension, articulated to other delimited criteria (age, health status, siblings). As one applicant explained to me: “At first I did not want to answer these questions ... I feel like I was discriminating. And then, I realized I had to express my limitations, what was possible for me".

The expression of racial desires is also a useful professional tool for helping social workers classify and categorise candidates based on their identified wishes. Professionals believe applicants must be able to verbalise "sincerely" - or "authentically" - their own parental desire. Indeed, their statements have to be, at the same time, consistent with institutional expectations but also freely and individually formulated. Contrary to their initial beliefs, when applicants do not specify their preference for a particular "origin" for their child, they expose themselves to an additional institutional suspicion; that applicants who not express racial desires, after several months of meetings and evaluations, might hide their “inner" racism. As a result, social workers are supposed to elaborate specific professional skills to flush it out. As Joanne, a middle-aged social worker, recalled one day:

"I remember parents... they were a disaster. When we went through the evaluation process, nothing went out. We did not suspect anything. At that time, we were less careful though. Well, you know... the father... he used to come with his daughter from Burundi, so cute... But this man was almost not capable of touching her. You know, due to her skin texture. (...) You could figure out he was disgusted. (...) We tried to fix things up.... But when you see this, you just blame yourself: we would never have left her with them."

If such episodes remain very rare in the daily activity of the bureau, they still appear as deeply and structurally consequential events. In fact, workers consider these "failures" as justifications for administrative action. Actually, it is because such situations exist that social control is justified and proven useful. They, at once, show the fragility of adoptable children, demonstrate the responsibility of the professionals, call for specific working skills, and reveal the potential duplicity of some adults who would hide their racism from the agents' sagacity. 
A few days later, I accompany Joanne to the first of the three interviews she planned with Mr. and Mrs. Guivarch, a wealthy couple in suburban Renangeours - the prefecture of the county. They are respectively 37 and 35 years old. He is a computer engineer, she holds a Masters of International Trade. They are both Catholics; he recounts with fondness memories of scouting, while she tells us that she used to teach catechism in the parish. Like most couples I met, Mr. and Mrs. Guivarch had previously undergone several IVF procedures. After four failures, they decided to start the adoption process, even if they admit that adoption "was not [their] initial project".

During the interview, Mr. Guivarch - certainly wanting to demonstrate his family's tolerance with respect to matters of racial diversity - explains that blackness "is not a problem" as his brother-in-law is Mozambican. He starts laughing as he reveals to us that his father welcomed his métis grandson "without any difficulties", even if he was stunned the first time his daughter introduced him to her future husband. Joanne raises an eyebrow. She scribbles notes in her notebook, pauses, and, facing up to M. Guivarch, asks him:

You told me you have a brother-in-law of colour... how did people react when he arrived?

Well, sure, this was not easy. In our family, there are not many people of colour.

Have you specifically mentioned to your father that he may have a grandson or a granddaughter of colour?

[Ironic] Well... it has happened already. Those he already has are a bit tanned. Hmm ... [Pause] But are these children integrated into the family?

[Visibly irritated] Sure. Of course, they are. Frankly.

But... Was there any mockery? You know... like "Blacks used to get the rhythm"?

No! It's not at all something my father would say.

Hmm ... [Pause] Are you talking with him about these issues?

Well, not exactly...

And why is that so hard to talk about it?

But it's not hard to talk about it... It's just something that does not pop up like that. (...)

I see... 
The conversation gradually turns contentious. A helpless spectator, Mrs. Guivarch wrings her hands on the nearby chair and tries to change the subject. After a few more minutes, Joanne decides it is time for us to leave. Back in the car, she explains to me she "do[es] not appreciate this couple", as "there is something wrong with them". According to her, "if the interviews keep going this way", she will "have to write a negative evaluation". A few weeks later, I attend with her the two remaining interviews with the Guivarches. Each time, the Mozambican brother-in-law's arrival into the family is mentioned, more or less insistently; each time, the question of racial diversity in the family structures the conversation, as Joanne attempts to elicit the assumed racism of the applicants and their relatives.

In her final report, Joanne pleads in favour of their parental project. However, she meticulously reports the conversation, and strategically details which she considers ambiguous in the couple's answers:

[Mr. Guivarch] suggests his sister and father had a 'more distant relationship' [...] which got worse when she married a man from Mozambique: '[It] was difficult for my father, he did not expect it and, thus far, there had never been a person of colour in our family'. However, if his father and nephews have a good relationship according to [Mr. Guivarch], he still detects a 'distance' between his father and sister, which he cannot explain, as he has not talked about it with them thus far. [...] [When] Mr. Guivarch talks about his nephews whose skin colour is different from their mother, he mentions it as a 'difference which has already been settled' in the past - when his sister publicized her wedding. He does not deny some reactions of astonishment and irritation with his father, although today allayed.

Social Report, September 2013

In the neutralized style of administrative rhetoric, reference to a long lasting "distance" between father and daughter (whatever the objective reasons), as well as the father's first reaction of "astonishment" and "irritation", are meaningful signs that will undoubtedly handicap the subsequent realisation of the adoption project. Many professionals who intervene later in the matching process between the child and the applicants (associations, NGOs, judicial authorities of the country of origin) will ask to read this report, 
and will interpret it. They might understand Joanne's hesitation as indicative of her racial qualms, and her concern about the risk of a potential rejection on grounds of race. The Guivarches may experience a longer period of waiting before any matching proposal and, accordingly, a lower probability to adopt.

As with the Guivarches, and contrary to most applicants' initial belief, racial preferences are considered less troubling than a supposed inability to express them. At the Bureau, professionals criticise racial desires less than they work at producing them. Paradoxically, what makes such professionals anxious is not the presence of preferences expressed in terms of race, but rather their absence, which justifies the deployment of sophisticated questioning techniques that are supposed to extort the truth about candidates' hidden racial feelings.

\section{Culture as condition}

One should not consider race as only meaningful in the field of international adoption, as national adoption in France is also saturated by racial concerns. Professionals from the Adoption Bureau do not only "prepare" parents who wish to adopt abroad by encouraging them to express troubling desires; they are also in charge of matching local available orphans to applicants who have specified their interest for national adoption in the first steps of the process. In these cases, race also appears as a professional criterion, although under different circumstances. In France, national adoption often (but not always) results from anonymous birth, which has been legal since the Revolution - initially to reduce the "risk of abortion", later on as recognition of a woman's right not to become a mother if she refuses to do so. Regardless of her nationality or of the resources available to her, anonymous birth ensures every woman the possibility of giving birth freely and anonymously in any French hospital. 
Her identity and the conditions of her admission are considered inviolable secrets. In 2002, though, a reform encouraged biological mothers to leave information about their health, and about the circumstances of their pregnancy and childbirth. If desired, biological mothers may also reveal their identities in a sealed envelope, which their children can access only upon turning 18 years old. Social workers of the Adoption Bureau are in charge of providing social and psychological support to biological mothers, and of entrusting children to professional nurseries. Biological mothers may recant during the first two months of their infants' lives, and demand that their parentage be established. If they do not, children may officially be declared "adoptable". A collegial guardianship body - named "Family Council" (Conseil de famille) - is then responsible for finding them adoptive parents. Family Councils are partially composed of professionals from local Adoption Bureaus, with whom they work closely, and of experts of "child issues" (such as paediatricians, psychologists, retired professors, etc.)

July 2013. This morning I join the head of the Adoption Bureau at a Family Council meeting to select Louis' new parents. We are twelve people in all, sitting around a table in a large room of the administrative district's main building. As required by law, several interests are represented here. Present are a state official of the Ministry of the Interior (the legal guardian of the ward), an elected representative of the Adoption Bureau's district, representatives of family associations, and "qualified individuals" who have been appointed by virtue of their expertise. Louis was born 3 months ago. His biological mother left some "personal information" in a sealed envelope that the child will be able to access when he turns 18. According to a note written by the social worker she has been in contact with, Louis's mother is supposed to be French, currently engaged in a relationship with the child's biological father, and has six children already: four boys and two girls (from 12 to 24 years old). She works as a maid in a cleaning business, and never finished junior high school. She has made mention of the identity of Louis" biological father. He is Tunisian, "by nationality 
and origin", and works as a bricklayer. The couple lives together and already educates "one child of whom Mrs X is not the mother". Her partner has been informed of the pregnancy, the delivery date and her relinquishment decision but, as mentioned in the report, "he has never met anyone from the Bureau". To the attention of Louis, his biological mother has added: "we want to offer you a better life. Our decision has nothing to do with you”.

Proceeding, the head of the Adoption Bureau presents aloud the social and psychological reports of three couples who have been previously approved to adopt Louis. These three applications have been preselected during a previous internal meeting at the Adoption Bureau, attended by social workers and psychologists only. Reports are sequentially read during approximately one hour and half, with almost no interruption or comment. This reading is soporific, as confirmed by the drowsy faces of the group members. Still, the head of the unit is committed to the procedure, as "it is the only moment members of the council learn about the applicants". Three couples are presented to the committee: the Blandiers, the Cardons, and the Bonnels. As in all the others cases I observed, the files presented are quite homogeneous, in terms of the social origin, age and matrimonial status of their subjects. All are heterosexual couples from 36 to 43 years old, with a history of unsuccessful IVFs. They all belong to the middle class, earning between 32,000 to 53,000 euros a year; their level of education is also similar. This homogeneity is unsurprising; as candidates who are submitted to the Family Council are selected amongst a happy few who passed all the previous tests, little diversity remains at this stage. One piece of information awakes the audience: Mrs. Bonnel's father was a migrant from Tunisia; however, the report states that Mrs. Bonnel grew up in France and never knew him, nor her father's family. Still, Family Council members nod, smile, and look at each other with signs of mutual understanding.

Once the reading is over, the representative in charge of facilitating the meeting motions around the table. Every Council member has to state his/her preference. The 
consensus is overwhelming. "The Bonnels". "The Bonnels again, for cultural reasons". "I pick up the Bonnels too. We already talked about it... Cultural issues... there will be most probably a recognition effect. Besides, I think this couple is ready. For them, it's now or never". "Well, I am not familiar with these couples but, to me, this is the Bonnels.

Obviously". "Mrs. Bonnel is of Tunisian origin. To me, that makes sense. The Bonnels"... Only once does a conflicting opinion arise, from a recently recruited social worker:

"Personally, I would respect the seniority. So, I am more in favor of the Cardons". An awkward silence surrounds us. But soon the representative in charge offers a rejoinder: "OK, but with the Bonnels, there will be a physical resemblance; it might make things easier. Let's vote now unless someone wants to add something, but we spent too much time on this already". Silence - so begins the vote. Except for the last speaker, everyone agrees and the Bonnels are selected. The representative, with a large smile on her face, concludes the meeting by stating: "Well, we had an easy baby to relate today..."

Observing such a collegial institution is very useful in analysing the way racial conformity is administrated. In this situation, "culture" appears as a ready-made criterion to arbitrarily produce and impose a decision based upon its members' own premises and projections of family normalcy. Thus, everything occurs as if ethical dilemmas that might arise from a partial consciousness of race-based discriminatory practices are both erased and debarred, by the seeming obviousness of a shared common sense turned into expertise. To mobilise the notion of "culture" is an effective way to counter objection: Reference to such a transcendent principle not only overwhelms any opposition, it also enforces professionals' feeling of usefulness and expertise, as they consider it their duty to protect the child's "birth culture" (Marre 2007), perceived as something both fragile and determinant.

In fact, the professional use of "culture" cannot be reduced only to the politically correct expression of "race" in a French administrative context. Professionals would be 
shocked if one suspected their actions and decisions to be fuelled by racially-based motivations, motivations that would narrow their choices, abilities and skills to a mundane operation of institutional segregation. But, at the same time, as racial heterogeneity is always perceived as potentially dangerous to the child, the spectral presence of race constantly influences the way professionals act and feel. If the idea of "culture" is so powerful and efficient, it is precisely because professionals sincerely consider they are acting "in the child's best interest" by inscribing new-borns within a performed, racialized, and imaginary filiation. Thus, these decisions are much less motivated by exclusion than by an intimate conviction of doing good and preserving the child's future. To the Council members, it did not matter that Mrs. Bonnel never knew her father with "Tunisian origins", nor whether Louis - who was just 3 months old - had ever lived with either of his biological parents. What mattered only was to create family ties that would serve to place a child in a naturalised environment, while at the same time marking his/her presumed difference and racial specificity.

Paradoxically in this case, as in many others I observed, it is this care for the others and the feeling of fulfilment of duties that accompanies it - that leads to racial discrimination. Indeed, the couples who are considered capable of adopting all kinds of children - once prepared - are uniformly white. On the contrary, "others" are viewed as naturally gifted to educate some. I discussed with social workers the previous cases of which they were in charge. No one remembered a French black or Arabic couple ever having been related to a white child"; but all of them proudly mentioned a number of white couples who were "open to racial diversity" and who had been entrusted with non-white children. Universalised competence in parenting is a white competence; on the contrary, couples "with origins" are more likely to be related with children who share with putative parents so-called "same cultural properties". 
Here, again, social workers, experts, and professionals are not "racist". To the contrary: During the long depth interviews I conducted with all of them, no one ever expressed any belief about white supremacy, nor defended white privileges. Indeed, they never considered their actions as racially-oriented. They always justified their choices, and their routines, by defending the "superior interest of the child" and - paradoxically - his/her right to be protected from the trauma of adoption. As a matter of fact, professionals frequently agree on the undesirability of adoption; although they all work to make adoption happen, they often regard this approach to family building as a default option to be considered only when all other possibilities have been exhausted.

The Family Council where I conducted my fieldwork has established its own criteria to select applicants. Being administratively certified was not enough to be considered as a potential parent. Applicants were only selected in case of infertility, and had to have been through several unsuccessful IVFs procedures. According to these professionals, adoption was not considered an option for those who would "have not tried to make babies". Hence, and contrary to the law, homosexual couples were never considered by Family Councils, nor single individuals. People who were older than 50 years old were never selected either. I have been told repeatedly that these local criteria - which are illegal and discriminatory, exceeding as they do the nationally defined regulations for delivering certification - have been established by members of the commission "to be more efficient", given "the number and quality of applications". (More than 200 files were on the waiting list, whereas 6 to 12 newborns only were taken in charge annually.) But these criteria were in fact indicative of another concern: when professionals were in charge of matching adoptive parents and children, they constantly tried to "reproduce nature" and to erase the supposed artificiality of their action. Although they worked on a daily basis at making families, they constantly tried to obscure their presence (and the one of the state) by creating "standard" families, coping with an 
idealised and fantasied definition of domestic happiness and normalcy, where "distance" between family members conformed with social expectations.

In this context, the defence of culture, and the consensus it forges amongst professionals, is a way to defend racial homogeneity amongst those who are considered to be others, as it prescribes not only what a family should be, but also what their family cannot become. In practice, favouring "culture" not only produces a sense of continuity which is supposedly beneficial to a child (who thereby has the capacity to access the roots which the apparatus creates for him/her); it also delineates boundaries that would benefit "the society" (Foucault, 2004b), by allocating specific children to specific applicants, and by determining always in order to do good - what, and who, one can expect as a coloured citizen in a colourblind society.

\section{Conclusion}

By analysing French institutional practices that regulate adoption, new dynamics emerge that help us to question the way family norms are implemented, racial distribution organised, and administrative work partly responsible for naturalising differences and hierarchies. Whereas French institutions are officially ruled by colour-blindness, adoption reveals how the administration deals in practice with racial diversity, and participates in defining and creating ideal families. Indeed, professionals determine the desirability of proposed arrangements on an unconscious racial basis, contrary to the "Republican ideal" where citizens are supposed to be - and to remain - racially undistinguished and undistinguishable. 
By turning to international adoption, one can observe how applicants are systematically invited to verbalise - and perform - racial desires, which in turn speak to the place "foreigners" are supposed to occupy both inside and outside the domestic unit. This politics of preventive verbalisation relies upon an ever-present fear of both rejection and racism, which leads social workers to implement specific techniques in order to unveil ostensible threats hidden within the applicants' psyches. In this context, intra-familial racial diversity has been gradually both perceived and constructed as a "problem" by expert discourses that, at the same time, suggest how to deal with the very "strangeness" they have participated in defining. Framed by institutions, subjects are encouraged to verbalise racial preferences; professionals encourage them to become able to express racial desires, while paradoxically - valuating current racial preferences as a mark of future non-racism. At the same time, by submitting applicants to a long process of evaluation and support, social workers and psychologists anticipate - and produce - latent racial dangers and risks. In return, this process requires professional action to diminish essentialised differences, rather than to question the naturalised standards that justify it. This work enforces strangeness as it perpetuates the idea that interracial family bonds require specific knowledge and management, and naturalises the assumption that familial legitimacy relies primarily on racial homogeneity.

Finally, as demonstrated by focusing on national adoption, the idea of race is partially replaced by the notion of "culture", which echoes a racialized perception of familial normalcy. Without ever publicly referring to skin colour, but while regularly mobilising the idea of "cultural heritage" or "roots", the racialized distribution of children reveals how care for others' lives and destinies might produce and maintain latent racial anxieties (Stoler 2010), which in turn generate the reproduction of racial hierarchies and inequalities. By determining who is able to adopt, love and educate whom, administrative institutions not only 
Version auteur - Acceptée pour publication

A paraître dans Social Anthropology

intervene in domestic units; they also enact what is the most desirable form of family

arrangement. By doing so, they delineate naturalised racial divides, which are rendered even more efficient and productive as they rely on a shared and consensual definition of ethics implemented not only amidst professionals, but also amongst families they are in charge of. Thus, racialization is not only a matter of discourses that produce differences; it is also a productive force that may occur in the name of love and comfort - a form of government always-already authorized and consensually accepted as adequate, necessary and ethically justified "for everyone's sake and happiness".

\section{Bibliography}

Briggs, L. 2012. Somebody's Children: The Politics of Transracial and Transnational Adoption. Durham: Duke University Press.

Choy, C. C. 2013. Global Families: A History of Asian International Adoption in America. New York: New York University Press.

Colombani, J-M. 2008. Rapport sur l'adoption. Paris: La Documentation française.

Denéchère, Y. 2011. Des enfants venus de loin: Histoire de l'adoption internationale en France. Paris: A. Colin.

Deomampo, D. 2016. Transnational Reproduction. Race, Kinship, and Commercial Surrogacy in India. New York: New York University Press.

Dorlin, E. 2006. La matrice de la race: Généalogie sexuelle et coloniale de la Nation française. Paris: La Découverte.

Dorow, S. 2006. Transnational Adoption: A Cultural Economy of Race, Gender, and Kinship. New York: New York University Press.

Eng, D. L. 2010. The Feeling of Kinship: Queer Liberalism and the Racialization of Intimacy. Durham: Duke University Press.

Fassin, D. et al. 2015. At the Heart of the State: The Moral World of Institutions. London: Pluto Press.

Fassin, D. and E. Fassin 2006. De la question sociale à la question raciale? Représenter la société française. Paris: La Découverte.

Foucault, M. 2004a. Abnormal. Lectures at the College de France (1974-1975). London: MacMillan.

Foucault, M. 2004b. Society Must Be Defended. Lectures at the College de France (19751976). London: MacMillan.

Howell, S. 2009. 'Adoption of the Unrelated Child: Some Challenges to the Anthropological Study of Kinship', Annual Review of Anthropology 38(1): 149-166.

Howell S. and D. Marre 2006. 'To Kin a Transnationally Adopted Child in Norway and Spain: The Achievement of Resemblances and Belonging', Ethnos 71(3): 293-316. 
Version auteur - Acceptée pour publication

A paraître dans Social Anthropology

Jerng M. C. 2010. Claiming Others: Transracial Adoption and National Belonging.

Minneapolis: University of Minnesota Press.

Kim, E. and B. Yngvesson 2011. 'Belonging in an Adopted World: Race, Identity, and Transnational Adoption', Anthropological Quarterly 84(4): 1047-1053.

Leinaweaver, J. 2008. The Circulation of Children Kinship, Mobility, and Morality in Ayacucho. Durham: Duke University Press.

Lieberman, R. 2004. 'A Tale of Two Countries: The Politics of Color Blindness in France and the United States', in H. Chapman and L. Frader (eds.), Race in France: Interdisciplinary Perspectives on the Politics of Differences, 189- 216. New York: Berghahn.

Marre, D. 2007. 'I want her to learn her language and maintain her culture': Transnational Adoptive Families' Views of 'Cultural Origins', in P. Wade (ed.), Race, Ethnicity, and Nation. Perspectives from Kinship and Genetics, 73-93. Oxford: Berghahn.

Mazouz, S. 2017. La République et ses autres. Politiques de l'altérité dans la France des années 2000, Lyon, ENS Éditions.

Melosh, B. 2002. Strangers and Kin: The American Way of Adoption. Cambridge: Harvard University Press.

Perreau, B. 2014. The Politics of Adoption. Gender and the Making of French Citizenship. Cambridge: MIT Press.

Quiroz, P. A. 2007. Adoption in a Color-blind Society. Lanham: Rowman \& Littlefield Publishers.

Rose, N. 1990. Governing the Soul: The Shaping of the Private Self. New York: Routledge.

Roux, S. and A-S. Vozari 2017. 'Parents at Their Best: The Ethopolitics of Family Bonding in France', Ethnography, OnlineFirst.

Saada, E. 2012. Empire's Children: Race, Filiation and Citizenship in the French Colonies. Chicago: University of Chicago Press.

Sabbagh, D. and S. Peer (eds.) 2008. 'French Color Blindness in Perspective: The

Controversy over "Statistiques Ethniques", French Politics, Culture \& Society, 26(1).

Seligman, J. L. 2013. Broken links, Enduring ties. American Adoption across Race, Class, and Nation. Stanford: Stanford University Press.

Stoler, A. L. 2010. Carnal Knowledge and Imperial Power: Race and the Intimate in Colonial Rule. $2^{\text {nd }}$ edition. Berkeley: University of California Press.

Treitler, V. B. (ed.) 2014. Race in Transnational and Transracial Adoption. Basingstoke:

Palgrave Macmillan.

Volkman, T. A. 2005. Cultures of Transnational Adoption. Durham: Duke University Press. Wade, P. (ed.) 2007. Race, Ethnicity, and Nation. Perspectives from Kinship and Genetics. Oxford: Berghahn Books.

Zelizer, V. 1994. Pricing the Priceless Child: The Changing Social Value of Children.

Princeton: Princeton University Press.

\footnotetext{
${ }^{\mathrm{i}}$ All data that could lead to identification have been transformed, in order to protect families, children, and social workers: names - obviously - but also ages, genders, countries of origin, number of siblings, etc.

ii As Pamela Anne Quiroz recalls, "transracial adoption" is a linguistic innovation that has been promoted for political purposes, aiming at valuing adoptive family bounds. This expression replaces nowadays "cross-racial" adoption, as "interracial" or "mixed-race" are substituted by "biracial" (Quiroz 2007: 42). In French, none of these expressions are used, as "international adoption" (adoption internationale) is already assumed to involve phenotypical differences.
} 
iii This article is based on research supported by the French National Research Agency (ANR) under the grant ANR-14-CE29-0002-01 (Program ETHOPOL). This work also received support from the CESSP (Paris) and the LISST (Toulouse). I am very grateful to Genevieve Zubrzycki for having invited me to present a preliminary version of this article in her seminar at the University of Michigan, and to Mathilde Darley, Jérémie Gauthier and Sarah Mazouz for their helpful comments during the workshop "Minorisation en actes" (Centre Marc Bloch, Berlin). I would also like to thank Daniel Frazier for his help during the editing process, and for his incredible knack for deciphering my frenglish.

${ }^{\text {iv }}$ Adoption in the French empire followed different trends, specifically as the racial order was under a much more nervous scrutiny (Saada 2012). This colonial past is still extremely vivid, as it has defined until now the racial hierarchies and anxieties that define contemporary (white) Frenchness. However, this genealogy only focuses on the so-called "métropole" (mainland France), as I aim more to describe juridical and institutional dynamics explaining the current apparatus.

' In January 2017, a French movie named Il a déjà tes yeux! was released in theaters, directed by Lucien Jean-Baptiste. In this comedy, a black couple adopts a white toddler, and must deal with various burlesque scenes of rejection before everybody recognizes the arrangement as legitimate. The comic effect relies on the supposed absurdity of such a matching in the French context, and the turmoil it provokes. 